Beware 31 January tax pitfalls

The summer economic statement may not have had much direct relevance to the profession, but one organisation is reminding dentists to be aware of what these changes mean.

Charles Linaker, a tax partner with NASDAL members UNW, says that the most important COVID-19 measure of which dentists need to be aware is a measure announced previously in relation to their 31 July payments on account due under Self-Assessment.

Linakar said: 'The majority of dentists will have had average earnings above the limits which might have rendered them eligible for help under the SelfEmployment Income Support Scheme and so, for them, the main measure of relief is the opportunity to defer their second payment on account for tax year 2019/20, due at the end of July, until next 31 January 2021, which was brought in as a response to COVID-19. By now, most dentists should have received their Self-Assessment statements from HMRC showing that their 31 July payment has been deferred automatically to 31 January 2021.

'This has been done so that HMRC's IT systems do not automatically charge late payment interest on any 31 July 2020 payment on account paid between 1 August 2020 and 31 January 2021. In other words, while it remains an option to make the payment as normal, should dentists choose not to, so as to preserve cash at this uncertain time, they need take no action to inform HMRC and will not be at risk of interest or penalty charges so long as the amount has been paid by no later than 31 January 2021.

Linaker continued: 'Of course, it may be argued that deferring until 31 January 2021 is doing no more than putting off the evil day and that there will then be a doubling up of tax payments, because the first payment on account will then be due for tax year 2020/21. But that is to overlook the fact that there is a long standing facility, of which many dentists may never have needed to take advantage previously in their professional careers, to make a claim to reduce the 2020/21 payments on account for 31 January 2021 and 31 July 2021, on the grounds that current year profits for 2020/21 will be reduced significantly compared to those for the preceding year 2019/20.'

\title{
Additional financial support and clear communication needed
}

The BDA has said the Scottish Government now has a responsibility to manage patient expectations, following confirmation from the First Minister that dental practices were able to offer routine care using non-aerosol generating procedures (AGPs) from 13 July.

Practices could only provide a limited range of treatments and will not be carrying out routine examinations. The BDA has stressed the need for clear and consistent communication from the Scottish Government and NHS Boards.

Dentists' costs have increased as practices began reopening last month. The Scottish Government has announced additional funding for the latest phase of reopening - a 30\% increase in General Dental Practice Allowance. While this funding is welcome, it is insufficient to restore practice income to pre-Covid levels and could see some practices struggle to remain viable. The BDA has stressed the need for additional funding, given the financial pressures facing mixed NHS-private practices with a high percentage of private income.

The Scottish Government has also issued a revised Statement of Dental Remuneration (SDR) for the next phase of reopening. The BDA welcomed the inclusion of triage activity in the SDR but has concerns about other aspects, such as the lack of funding for lab bills and the reduced level of care that GDPs are able to provide when routine examinations restart in phase 3.

David McColl, Chair of the Scottish Dental Practice Committee said: 'The Scottish Government has a responsibility to manage patient expectations. Yes, we are moving to the next phase of reopening, but very little will change in terms of the treatments we can offer to our patients.

'Routine dentistry has not returned, and this fact needs to be clearly communicated. Dentists now face a vast backlog of dental treatment, and it will be some time before we return to anything resembling 'business as usual'.

'Ministers now need to provide appropriate financial support to ensure the sustainability of NHS dentistry. We need the Government to engage more regularly and effectively with the profession and the public as we continue to navigate our way through these difficult times.'

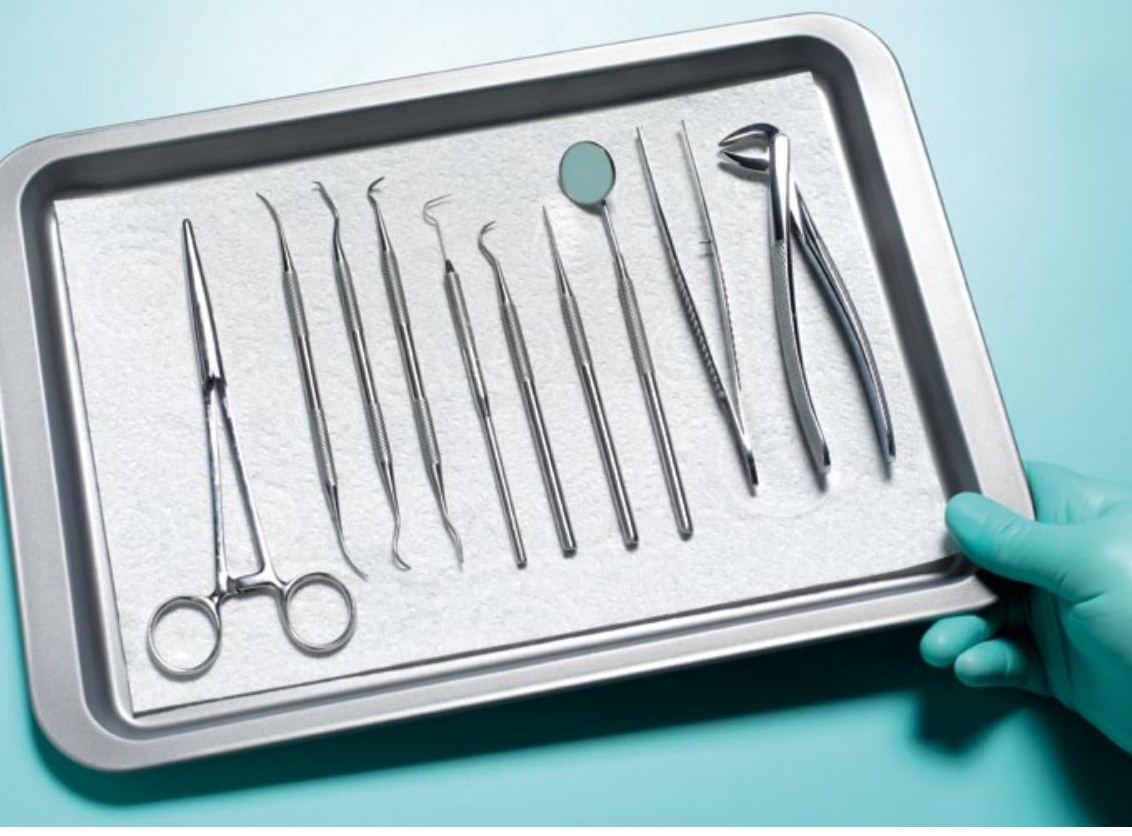

